\title{
A DISTÂNCIA: A ESCOLA LULA PARA A FORMAÇÃO DE PROFESSORES
}

\author{
Maria de Fátima Rodrigues Pereira
}

(UTP/Brasil)

Elza Margarida de Mendonça Peixoto

(UEL/Brasil)

\section{RESUMO}

A educação a distância com novas tecnologias de informação e comunicação (TICs) estrutura-se, no Brasil, a partir da década de 1970, porque, também a partir de então, as TICs foram associadas ao processo produtivo. A educação a distância com TICs compõe uma conjuntura histórica de transição de um trabalho sob a gerência fordista para o toyotismo. Se, sob o fordismo as relações de trabalho se caracterizavam pelo caráter parcelar, fragmentado, da indústria seriada, da produção em série; sob o toyotismo o trabalho caracteriza-se pela flexibilização, a desregulamentação, a polivalência. Estas mudanças na base produtiva, do mundo da "empresa flexível, como diz o capital, ou do mundo da acumulação liofilizada, não alteram a forma de ser do capital, mas alteram, em muito, o que se pede à educação. Os que defendem a educação a distância com TICS apontam seu potencial de promover cidadania: demandas de difícil atendimento podem ser atingidas; possibilitam encurtamento de distâncias entre sujeitos e informações. Analisamse as políticas de educação a distância, em curso no Brasil, nomeadamente para a formação de professores. Recorre-se às contribuições da ciência política e da reflexão ontológica para este entendimento. O objetivo é contribuir com o debate, as práticas e as políticas de formação de professores.

Palavras-chave: políticas, educação a distancia, formação de professores.

\section{A DISTANCIA: LA ESCUELA LULA DE FORMACIÓN DE PROFESORES}

\section{RESUMEN}

La educación a distancia con nuevas tecnologías de información y comunicación (TICs) se estructura, en Brasil, a partir de la década de 1970, porque, también a partir de entonces, las TICs fueron asociadas al proceso productivo. La educación a distancia con TICs compone una coyuntura histórica de transición de un trabajo bajo la gerencia fordista para el toyotismo. Si, bajo el fordismo las relaciones de trabajo se caracterizaban por el carácter parcelar, fragmentado, de la industria seriada, de la producción en serie; bajo el toyotismo el trabajo se caracteriza por la flexibilización, el desreglamento, la polivalencia. Estos cambios en la base productiva, del mundo de la "empresa flexible, como dice el capital, o del mundo de la acumulación liofilizada, no alteran la manera de ser del capital, pero alteran, en mucho, lo que se pide a la educación. Los que defienden la educación a distancia con TICS apuntan su potencial de promover ciudadanía: demandas de difícil atención pueden ser atingidas; posibilitan acortamiento de distancias entre sujetos e informaciones. Se analizan las políticas de educación a distancia, en curso en Brasil, nombradamente para la formación de profesores. Se acude a las contribuciones de la ciencia política y de la ponderación ontológica para esta comprensión. El objetivo es contribuir con el debate, las prácticas y las políticas de formación de profesores.

Palabras-clave: políticas, educación a distancia, formación de profesores. 


\section{Introdução}

A educação a distância com novas tecnologias de informação e comunicação (TICs) estrutura-se, sobretudo, a partir da década de 1970, não por acaso, e, sim, porque também a partir de então, as TICs foram associadas ao processo produtivo de bens no modo de existência capitalista. Portanto, a educação com TICs compõe uma conjuntura histórica de transição de um trabalho sob a gerência fordista para o toyotismo. Se, sob o fordismo as relações de trabalho se caracterizavam pelo caráter parcelar, fragmentado, da indústria seriada, da produção em série; "no binômio taylorismo/fordismo, a concepção e a elaboração são responsabilidade da gerência científica, a execução (manual) é responsabilidade dos trabalhadores" (ANTUNES, 2009).

Sob o toyotismo, o trabalho caracteriza-se pela flexibilização, a desregulamentação, a polivalência.

Quem conheceu uma fábrica, como ela era na era taylorista-fordista e vê uma fábrica hoje, percebe que a diferença é visível no seu desenho espacial, de trabalho, de organização técnica e de controle do trabalho. Não tem mais as divisórias. Não tem mais o restaurante do "peão" e o restaurante da gerência. É aparentemente mais "participativa", aparentemente mais envolvente e aparentemente menos despótica.

Em contrapartida, o trabalho é mais desregulamentado, mais informalizado, mais precarizado, mais intensificado, mais "polivalente", mais "multifuncional", seguindo critérios de "metas", "competências", etc. É feito em equipe, onde a competição é terrível entre os trabalhadores e as trabalhadoras. O toyotismo só pode viver - e as formas distintas de empresa flexível - com base no envolvimento, na expropriação do intelecto do trabalho. Então certamente o Taiichi Ohno (engenheiro fundador desse receituário) não concordaria com a máxima do Taylor de que o trabalhador é só um "gorila amestrado". Isso configura uma alienação que é mais interiorizada. O trabalhador e a trabalhadora têm que se envolver. Ele não é mais trabalhador, é definido como "colaborador ou colaboradora", "consultor". A alienação/estranhamento é aparentemente - atenção! - aparentemente menos despótico, mas intensamente mais interiorizado. Porque é assim que o toyotismo pode envolver. E para que haja o envolvimento, tem que fazer algumas concessões, senão não há base para o envolvimento. Na fábrica taylorista e fordista tradicional o despotismo é explícito. Da planta flexível, eu usei no livro Adeus ao Trabalho? a seguinte fórmula: as empresas querem converter os trabalhadores em déspotas de si mesmos! (ANTUNES, 2009).

Estas mudanças na base produtiva, do mundo da "empresa flexível, como diz o capital, ou do mundo da acumulação liofilizada, não alteram a forma de ser do capital" (ANTUNES, 2009), mas alteram, em muito, o que se pede à educação. A educação a distancia faz parte destas mudanças.

Este texto apresenta as políticas para a educação a distancia nas duas últimas décadas no Brasil, analisa-as à luz da ciência política para investigar as dimensões de cidadania que prometem. Recorre à literatura sobre o tema para aprofundar o debate e contribuir para práticas sociais emancipadas. 


\section{Educação a Distância: da periferia ao centro das políticas educacionais}

Já nos anos 1960, na Europa, nos países centrais do sistema, a educação a distância institucionalizou-se com várias ações na educação secundária e superior para trabalhadores (NUNES, 2009, p. 2). Na década de 1970, a Inglaterra, Alemanha e Espanha criaram Universidades Públicas com ensino a distância voltadas ao atendimento de milhares de estudantes trabalhadores com custos mais baixos (GATTI, 2009, p.89).

No Brasil, um dos primeiros cursos, o Projeto Logos, data da década de 1970. Desde então vêm os primeiros programas a distância: o Projeto Minerva; o Telecurso 2000 - cujo objetivo foi prover formação geral de nível médio; o Proformação - dirigido a professores leigos; Um Salto para o Futuro - destinado à formação continuada de professores de $1^{\mathrm{a}}$ a $4^{\mathrm{a}}$ séries e de educação infantil, e alguns cursos de licenciatura.

Entretanto, nesta fase inicial, a educação a distância caracterizou-se pela descontinuidade e instabilidade, foram iniciativas de pesquisadores, centros universitários, com algum consentimento e incentivo do MEC, sobretudo do Ministério de Ciência e Tecnologia (MCT). Na década de 1990, de espectador e incentivador, o governo brasileiro passou a ser interventor. Importantes decisões foram tomadas para a EAD: em 1992 o MEC criou a Coordenadoria Especial de Educação a Distância e, em 1995, a Secretaria de Educação a Distância (SEED). A Lei de Diretrizes e Bases da Educação Nacional, de 1996, abriu novas possibilidades de desenvolvimento da EAD no país, estabelecendo, em seu art. 80, que "o Poder Público incentivará o desenvolvimento e a vinculação de programas de ensino a distância em todos os níveis e nas modalidades de ensino, e de educação continuada".

Se o governo Fernando Henrique Cardoso criou órgãos e garantiu a EAD na Lei de Diretrizes e Bases da Educação, é o governo Luis Inácio Lula da Silva que implanta, efetivamente, a política de educação a distancia para o nível médio de ensino e formação de professores. Entende-se, então, que a EAD é um fenômeno que tem fases e que atinge efetivação com o governo Lula.

Poder-se-ia, então, fazer dois períodos para este processo que se denomina da periferia ao centro das políticas educacionais: o primeiro, da década de 1970 até à década de 1990, caracterizado pela oferta de cursos a distância, predominantemente com uso de TV e vídeo, em caráter temporário, dirigido a populações pouco escolarizadas, como foi o Projeto Minerva; ou voltados à formação de professores leigos, como o Projeto Logos. Não se cogitou, na criação de uma Universidade, sistema e ou rede para a EAD. Foi um tempo de experimentos, ensaios, debates levados a cabo por algumas universidades. Em 1971, foi realizado Seminário intensivo sobre o uso de computadores no ensino de Física na Universidade de São Carlos. Também ocorreu a Primeira Conferência Nacional de Tecnologia em Educação Aplicada ao Ensino Superior (I CONTECE), no Rio de Janeiro, promovida pelo Conselho de Reitores das Universidades Brasileiras. Passados dois anos, em 1973, o Núcleo de Tecnologia Educacional para a Saúde e o Centro Latino Americano de Tecnologia Educacional (NUTES/CLATES) da Universidade Federal do Rio de Janeiro (UERJ) usaram software de simulação no ensino de química (VALENTE, p. 6). No ano seguinte, foi a vez da Universidade Federal do Rio Grande do Sul (URGS) realizar experiências, usando simulação de fenômenos de física com alunos de graduação. Na mesma Universidade foi desenvolvido, pelo Centro de Processamento de Dados, o software SISCAI para avaliação de alunos de pós-graduação em Educação, adaptado, em 1982, como sistema CAI no ensino de $2^{\circ}$ grau pelo grupo de pesquisa da Faculdade de 
Educação (FACED), liderado pela Profa. Lucila Santarosa (Idem). Na Universidade Estadual de Campinas (UNICAMP) foram desenvolvidos softwares (VALENTE e MARTINELI) para uso de alunos de Mestrado em Ensino de Ciências e Matemática coordenado pelo Prof. Ubiratan D' Ambrósio, no Instituto de Matemática, Estatística e Ciência da Computação, com financiamento da Organização dos Estados Americanos (OEA) e Ministério da Educação (MEC). Em 1975, com a primeira visita de Seymour Papert e Marvin Minsky ao Brasil, foram lançadas as ideias de $\operatorname{Logo}^{1}$ que, em 1976, com a segunda vinda para colaborarem com o grupo de pesquisa sobre o uso de Logo em educação, foram iniciados os trabalhos com crianças. Estes trabalhos tiveram desdobramentos na pesquisa em educação e novas tecnologias, no ensino e na criação de grupos. Inscreve-se neste conjunto a dissertação de Mestrado de Maria Cecília Calani (1981), a Criação do Núcleo de Informática Aplicada à Educação (NIED), em maio de 1983, e as propostas e práticas do laboratório de Ensino e Estudos Cognitivos (LEC) da UFRGS, liderado pela Profa. Léa da Cruz Fagundes, que se debruçou sobre as dificuldades de aprendizagem da matemática e as contribuições de Logo nos processos cognitivos de alunos de 7 a 15 anos.

Ainda na década de 1980 uma série de eventos e programas promoveu a implantação de laboratórios e recursos humanos. Em Brasília (1981) e Salvador (1982) deu-se a realização do Seminário Nacional de Informática em Educação, respectivamente I e II, com desdobramentos como O EDUCOM, que possibilitou a formação de pesquisadores nas universidades e escolas públicas e que teve o apoio da Secretaria Especial de Informática (SEI), do Ministério da Educação e Cultura - MEC, CNPq, FINEP, Ministério da Ciência e Tecnologia - MCT; também a oferta do curso de Especialização em Informática em Educação (FORMAR); a criação, nos Estados, da Federação dos Centros de Informática e Educação - CIEds e nas Escolas Técnicas Federais.

O segundo período, já na década de 1990, caracteriza-se: (1) pela criação de órgãos de governo para a educação a distância; (2) pela chegada ao mercado de microcomputadores a custos menores e seu uso para o armazenamento de dados e informações e, (3) fundamentalmente, pela política de apoio, incentivo, autorização de atividades, credenciamento de instituições para a oferta de cursos e programas de educação a distância.

No prazo de três anos o Governo FHC, em uma política de continuidade, criou, em 1992, a Coordenadoria Nacional de Educação a Distância no Ministério de Educação e Cultura - MEC, seguida, em 1995, da Secretaria de Educação a Distância (SEED). A Lei de Diretrizes e Bases da Educação Nacional, Lei 9394/96 consagrou atenção à EAD no País, dedicando-lhe o art. 80, exarando que "o Poder Público incentivará o desenvolvimento e a vinculação de programas de ensino a distância em todos os níveis e nas modalidades de ensino, e de educação continuada". À União ficou reservado o credenciamento das instituições para esse fim, cabendo aos respectivos sistemas de ensino as normas para a produção, controle e avaliação de programas de EAD e a autorização para a sua implementação (Brasil, 1996).

Em 1997, foi a vez do Programa Nacional de Informática na Educação - Proinfo vinculado à SEED, que possibilitou a implementação, até ao final de 1998, de 119 Núcleos de Tecnologia de Informação (NTE) em 27 Estados e capacitou cerca de 1.419 professores para atuarem nos NTEs. Ainda em 1997 a SEED/MEC, através do Fundo de Fortalecimento da Educação (FUDESCOLA) e Secretarias municipais, propôs o Programa Proformação - Programa de Formação de Professores em Exercício para Habilitação de Professores - que contou com financiamento do Banco Mundial e parceria do Programa das Nações Unidas para o Desenvolvimento (PNUD). Em 2002 passou a ter financiamento 
do Fundo Nacional de Desenvolvimento (FNDE), que de 1999 a 2004 habilitou aproximadamente 30.000 professores nas Regiões Norte, Nordeste e Centro-Oeste.

Em 1998, os participantes da Conferência Mundial sobre Ensino Superior, convocada pela UNESCO, entendiam que as dificuldades de acesso à educação podiam ser equacionadas mediante a utilização das tecnologias de informação e comunicação (TICs), o que possibilitaria a democratização desse nível de ensino e a custos menores.

No mesmo ano da Conferência, o Ministério da Educação promoveu a regulamentação de EAD por meio dos Decretos ns. 2.494/98 (BRASIL,1998 ${ }^{\text {a }}$ e 2561/98 (Brasil, 1998b) e a portaria n. 301/98 ( Brasil. MEC, 1998). Esta última normalizou os processos de credenciamento de instituições que se propunham a oferecer cursos de graduação e educação profissional tecnológica a distância, abrindo a possibilidade de parcerias e convênios entre instituições. O MEC também se apressou, em 1998, a publicar o documento - Indicadores de Qualidade para Cursos de Graduação a Distância, visando orientar as instituições proponentes dos cursos de EAD. Destaque-se o caráter somente orientador, sem força de lei. Nestas condições é que foi oferecido o Telecurso 2000, criado em 1994.

O documento dos Indicadores de Qualidade para Cursos de Educação a Distância não deixou dúvidas ao expressar que a educação a distância se daria pela autoformação mediada pelas tecnologias de comunicação e informação, expressão de uma perspectiva individualista de formação humana e da neutralidade das informações, das máquinas, dos princípios explicativos que informam os programas e informações disponibilizadas.

Esta política claramente tecnicista sinalizava para os professores que podiam ser dispensados (LIBÂNEO, 1998), que o investimento estava agora centrado nas tecnologias. Em decorrência, bibliotecas ricas de obras de clássicos do pensamento histórico e sociológico brasileiro foram parar em depósitos escuros e úmidos, para darem lugar a computadores obsoletos da IBM, importados ao abrigo de convênios pouco claros, ou de doações generosamente feitas pelas empresas de informática aos brasileiros.

Embora tendo criado a Secretaria, o governo apenas se atribui, por enquanto, predominantemente, a política de autorização e de apoio a projetos que lhe eram encaminhados, de educação a distancia, a exemplo do Telecurso 2000.

Ao final da década de 1990 a EAD começa a sair da periferia das políticas educacionais, num processo de realização de ações e estratégias emergenciais para dar conta de problemas graves e imediatos na educação, como o analfabetismo e a qualificação de trabalhadores e, particularmente, da formação de professores. Com o governo Lula, a EAD adquiriu centralidade no cenário educacional, especialmente no nível médio, educação profissionalizante e superior, com destaque para a formação inicial e continuada dos professores.

\section{Consórcios, redes, programas, centralidade da educação a distancia}

As mudanças no mundo produtivo vêm demandando metamorfoses na educação e na formação de professores. Os organismos mundiais encarregam--se de expressar em documentos que o atual estágio da economia e desenvolvimento necessita de educação. Neste sentido, redes, consórcios e programas encarregam-se de difundir ideologias como a das TICs promotoras de expandir democracia, passaportes vitalícios de acesso à sociedade do conhecimento contratam assessorias para planejamentos e execução de cursos de formação inicial ou continuada, capacitação, treinamento, reciclagem, os professores recebem designações de tutor, monitor, facilitador, animador, professor gestor. As TICS 
são apresentadas como a solução para a "baixa produtividade" das universidades e para o caráter excessivamente teórico da formação de professores. Segundo documentos do Banco Mundial, específico para professores do Brasil, as redes têm se mostrado um dos catalisadores mais eficientes para a formação de professores e contínuo reforço de treinamento (DELANNOY E SEDLACEK, 2000, APUD EVANGELISTA E SHIROMA). Para tal montam-se redes que podem ser privadas, privadas e públicas, ou só públicas

Duas redes para a América Latina e Caribe merecem destaque: a REDE Kipus de Formação Docente, pertencente à UNESCO e PREAL - Programa Regional da Reforma Educativa na América Latina.

As atividades do PREAL recebem apoio da United States Agency for International Developement (USAID), Banco Mundial, Fundação General Eletric, entre outros. Do PREAL participam brasileiros da mais alta expressão no cenário educacional, como o ex-Ministro da Educação, Paulo Renato de Souza (1994-2002), assessores do BID e banco Mundial, como Cláudio Moura e Castro e Guiomar Namo de Mello, a ex-presidente do Instituto Nacional de estudos e Pesquisas Educacionais Anísio Teixeira (INEP), Maria Helena Guimarães (EVANGELISTA E SHIROMA, p. 39).

Interesses de frações do capital compõem as redes, infiltram-se através de seus agentes de plantão, influenciam políticas, controlam a sua implementação.

\begin{abstract}
Identificando os membros brasileiros que participam do GT Profissionalização Docente (GTD) no PREAL e mapeando os cargos públicos que já ocuparam, vínculos com Organismos Internacionais e as organizações a que pertencem atualmente, encontramos diversos tipos de relações interessantes que evidenciam que este GT é formado por ex-membros do executivo, do CNE, do INEP, que ocuparam postos estratégicos no cenário educacional e, agora fora do aparelho do Estado, atuam como consultores, formadores e assessoram a implantação de reformas educacionais em vários estados, municípios e fazem a formação de gestores atuando em parceria com várias Secretarias da Educação, União Nacional de Dirigentes Municipais de Educação (UNDIME) ou Conselho Nacional de Secretarias de Educação (CONSED). Cite-se a atuação de Paulo Renato de Souza que, estando à frente do Ministério da Educação (MEC) nos governos HFC, junto ao Conselho Nacional de Educação (CNE) e INEP, exigiu determinadas adequações dos sistemas educacionais, escolas e professores por meio de várias reformas educacionais em sua gestão (1994-2002) (IDEM).
\end{abstract}

Estes intelectuais orgânicos da burguesia, enquanto governo, interferem diretamente na formulação de políticas educacionais de formação de professores. Fora dos aparelhos de Estado organizam-se em redes de formadores de opinião, de coerção e consentimento para a implantação, ainda, das políticas que favorecem os interesses do capital. Paulo Renato - atualmente Secretário de Educação do Estado de São Paulo - ao deixar o MEC, criou a empresa Paulo Renato de Souza Consultores, com ex-membros do MEC. Entre os clientes deste gabinete de assessores estão o Banco Mundial, o BID, Editora Moderna, Grupo Positivo, Fundação Gerdau, Fundação Jacobs, Fundação Lemann, que, por sua vez, são contratados por Secretarias Estaduais, Municipais de Educação, Institutos e ONGs. Enfim, as redes de influência se entrelaçam e os muros entre o público e o privado, avocados ingenuamente para a defesa ambígua de interesses populares, caem por terra. Os muros aparentemente existentes esvanecem-se no meio dos interesses comuns das mercadorias. Aliás, não é por acaso que as grandes corporações inventaram a chamada "Universidade Corporativa".

Universidades públicas ainda discutem uma sociedade alternativa, outro modo de produção e de vida, as formas de reinvenção do socialismo, eles (os ideólogos do capital) criam a Universidade Corporativa. Eles querem 
forjar seus quadros lá dentro das empresas. Aliás, não pode haver maior contradição em termos: uma universidade corporativa: universidade lembra universalidade; corporação lembra restrição, interesses restritos e específicos. Qual a nova pragmática da educação do capital em nossos dias: no ensino superior, expandem-se os cursos flexíveis! Núcleo básico para curto, rápido, no menor tempo de escolarização. Ensino não presencial. A real substância do ensino não conta. Você fala para alguns milhões e não tem mais o contato presencial. É na verdade uma pragmática flexível para uma sociedade liofilizada (Parêntese: como liofilização não é um termo das ciências sociais, uma explicação rápida. $\mathrm{Na}$ química, liofilizar significa, em um processo de temperatura baixa, secar, reduzir as substâncias vivas. O leite em pó é um leite liofilizado. Então você seca a substância (ANTUNES, 2009).

Neste contexto, em 1999, um grupo de aproximadamente 50 universidades federais decidiram criar a Unirede, um consórcio virtual de universidades para desenvolver programas de graduação e pós-graduação strictuo-sensu e lato-sensu. Em 3 e 4 de Dezembro de 1999, ocorreu um Seminário das Universidades Brasileiras Virtuais para discutirem sobre como promover os projetos de EAD e cursos on-line. Em processo contínuo, em 2000, foram formados quatro grupos de trabalho para prepararem a estrutura organizacional, a tecnológica e mídia interativa, o apoio operacional e o produto da UniRede Virtual. Em 12 de abril de 2000 o Ministro da Ciência e Tecnologia indicou um grupo de trabalho para elaborar o projeto de infraestrutura para estabelecer a Universidade Virtual Pública Brasileira UNIREDE. De 9 a 14 de julho deu-se a realização da Primeira Exposição de Educação a Distância da UNIREDE, durante a 52 ${ }^{\mathrm{a}}$ Reunião da Sociedade Brasileira para o Progresso da Ciência (SBPC). E, em 2001, foram criados dois Consórcios: UVB - Universidade Virtual do Brasil e a RICESU - Rede de Instituições Católicas de Ensino Superior, integrado por oito universidades consorciadas. Em 2001 deu-se o lançamento da Revista Col@bora, durante o Congresso Abed de Educação a Distancia. Em 2001 a UFMT, UFSC, UFPE, UNICAMP, UFPR já se apresentavam fortemente envolvidas com a educação a distância. O MEC, em 2001, pela Portaria $2.253 / 2001$, abriu a possibilidade da oferta de cursos com carga horária de até $20 \%$ da carga total, na modalidade não-presencial. No mesmo ano, o Plano Nacional de Educação, Lei n. 10.172/2001, reitera a importância da EAD nas políticas de educação; estabelece diretrizes, objetivos e metas para sua implementação; apoio financeiro às pesquisas sobre EAD. As críticas aos Referenciais de Qualidade de 1998 provocaram alterações.

Em 2003 foram formulados novos referenciais que orientavam (1) critérios de credenciamento das instituições; (2) mecanismos para coibir abusos; (3) padronização das normas e procedimentos entre os Conselhos Estaduais de Educação e o Conselho Nacional de Educação; (4) atendimento às pessoas com necessidades especiais, indicações sobre aspectos pedagógicos, (5) recursos humanos, (6) infraestrutura a ser observada pelos cursos, contemplando: compromisso dos gestores; desenho do projeto; transparência nas informações; equipe profissional multidisciplinar; comunicação/ interação entre os agentes, recursos educacionais, infraestrutura de apoio, avaliação contínua e abrangente, convênios e parcerias, e sustentabilidade financeira. A Portaria 4.059/04 de 2004, face aos abusos, esclareceu que os $20 \%$ da carga horária se referiam ao total da carga horária do curso.

Com o edital 001/2004, elaborado com base nos dados do Censo de Profissionais do Magistério de 2003 que apontavam déficits de professores no ensino médio e de docentes com formação específica em $5^{\mathrm{a}}$ e $6^{\mathrm{a}}$ séries, o MEC convocou as universidades públicas a oferecerem cursos de licenciatura em Pedagogia, Física, Química, Biologia e 
Matemática. Foram selecionados oito consórcios, totalizando 39 IES, que ofereceram 19 cursos em todas as regiões do país para atender a 17. 585 alunos (GATTI, 2009, p.97).

A SEED institui uma comissão de acompanhamento das instituições consorciadas com a finalidade de ampliar o número de oferta de vagas e atender o Programa PróLicenciatura da Secretaria da Educação Básica. Por sua vez, o consórcio UniRede enviou ao MEC documento com medidas necessárias à consolidação da educação a distância.

No sentido de regulamentação das Diretrizes dos Referenciais de Qualidade, em 2005 foi publicado o Decreto 5.622/2005 que revê o Decreto 2.494/1998 e a Portaria 3.001/1998. Se o foco pelo Decreto anterior estava nos recursos e suportes de informação, neste a ênfase passa a ser a mediação didático-pedagógica. Avanço em relação à tendência tecnicista anterior? O Decreto também define que, para algumas áreas, os cursos devem ser submetidos aos Conselhos Regionais, que os diplomas da EAD passam a ter a mesma validade dos diplomas presenciais. Determina ainda que os Referenciais de Qualidade para a Educação a Distância, definidos pelo MEC, devem pautar as regras para a regulação, supervisão, e avaliação. Os referidos Referenciais estabelecem a preponderância da avaliação presencial, maior explicitação dos critérios para credenciamento institucional, sobretudo, no que se refere aos pólos descentralizados de apoio aos alunos, mecanismos para coibir abusos, como a oferta desmesurada de vagas no ensino superior, colaboração entre Conselhos de Educação, Secretarias e IES.

Ainda em 2005, o ministério inclui na sua agenda o Fórum com as Estatais pela Educação cujo objetivo da criação do sistema Universidade Aberta do Brasil (UAB) para atuação na formação inicial e continuada de professores da educação básica com a utilização de metodologias de educação a distância. No ano seguinte, pelo Decreto $\mathrm{n}$. 5.800, o MEC instituiu o Sistema Universidade Aberta do Brasil, ligada à Capes, em pareceria com a SEED. Com a articulação entre IES públicas de ensino superior, estados e municípios, a UAB propõe-se a expandir e levar aos interiores do Brasil cursos de educação superior pública, para gestores e trabalhadores, educação básica e apoiar pesquisas sobre EAD. Ainda em 2007, foram selecionados 27 polos para atenderem a 673 turmas e 32.880 vagas. No mesmo ano esta política de formação a distância de professores foi fortalecida com a atribuição à CAPES de coordenar o Sistema Nacional de Formação, ao INEP o papel de acompanhar, e ao FNDE, de financiar; sobretudo, para a formação de professores. No mesmo ano, o MEC, por meio da SEED estabeleceu novos Referenciais de Qualidade para EAD, reforçando (1) a necessidade dos cursos a distância se pautarem pelo Projeto Político Pedagógico, (2) a atenção que devem merecer os estudantes, (3) a interação professor-aluno, coordenadores, equipe administrativa, o material didático, instalações.

Em 2008, o governo do Estado de São Paulo lançou a Universidade Virtual do Estado de São Paulo (UNIVESP). O MEC, pela Portaria n. 1.050 induziu a oferta pública de cursos superiores a distância pelas instituições públicas de educação superior no âmbito do Sistema UAB. Finalmente, na Reunião Anual da ANPED/2008, Fernando Haddad, ministro da Educação, comunicou a Criação da CAPES 2 e a inserção da EAD como área de reconhecida importância no cenário educacional.

Pode-se concluir que, com a Universidade Aberta do Brasil e o Programa PróLicenciatura, se está perante uma efetiva política do governo Lula para a formação a distância de professores. Mais: é uma política que se fortalece com a atuação da CAPES, INEP, FNDE e SEED. As políticas do Governo Lula de formação de professores a distância são uma nova reforma? Já não há dúvida que a formação de professores, quando feita a distância, ganha nova configuração (GATTI, 2009). Se durante o Governo FHC, o MEC avançou, regulamentando e autorizando, em 2006, o governo Lula deu um passo à 
frente ao instituir o sistema Universidade Aberta do Brasil, a cargo da Diretoria de Educação a Distância do MEC, ligada à Capes, uma medida que surpreendeu a muitos por atribuir à Coordenação de Aperfeiçoamento de Pessoal de Nível Superior a responsabilidade pela formação de professores em nível de graduação. Esta tarefa foi assumida em parceria com a SEED. Formaram-se redes, consórcios de instituições públicas, fundacionais e privadas. Arrumaram-se recursos, produziu-se legislação, critérios de referencias de qualidade para a EAD. "De 107 cursos de graduação em 2004, passou-se a 408 em 2007; e, das 59.611 matrículas em 2004, chegou-se a 369.766 em 2007". (GATTI, 2009, p. 104).

\section{Educação a distância: qual cidadania, qual ontologia?}

Os que defendem a educação a distância com TICS apontam seu potencial de promover cidadania, pois: (1) podem ser atingidas demandas de difícil atendimento, (2) possibilita encurtamento das distâncias, entre sujeitos e informações, (PRADO, VALENTE, 2002), (3) possibilita pôr em contato contextos distintos, atuando em redes "configurando novos caminhos [...] e compreensões sobre o mundo e sobre a cultura" (IDEM); (4) tendem a fortalecer processos democráticos; (5) as mídias favorecem uma formação reflexiva contextualizada; (6) igualmente colaboram na socialização dessas práticas contextualizadas (7) favorecem múltiplas interações entre os participantes; (8) possibilitam interação com diferentes interlocutores; (9) ampliam o escopo de relações e de compreensão do educador-aluno, favorecendo a transcendência da compreensão do local e universal

Pois bem, é já consenso, mesmo para alguns que professam otimismo tecnológico, que as TICs, servem a projetos históricos das classes e frações de classe no atual modo de existência. As políticas educacionais decididas nos organismos mundiais e implementadas com ajustes no Brasil têm se pautado por uma visão econômica da educação, ou seja: a educação é vista como um insumo, contabiliza-se investimento e resultados, tem-se preferido investir em tecnologia, livros didáticos, em treinamento tácito dos professores, do que propriamente em formação científica e filosófica necessária a formação de gerações. Tem-se, também, que a hegemonia dos interesses do capital tem feito o exercício de, através das políticas educacionais a distância, ampliar extraordinariamente a reprodução da força de trabalho e contribuir para uma despolitização e ausência de transferências de visões de mundo, absolutamente necessárias à plena realização emancipada de todos os seres humanos. Portanto, se está face a cidadanias restritas e a ontologias individualistas e excludentes, por serem características do projeto histórico hegemônico. Porém, o atual modo de existência é atravessado pela contradição, as tecnologias são meios e não fins e, portanto, podem ser postas a serviço de uma ontologia e ética verdadeiramente humana. 


\section{Referências}

ANTUNES, Antunes, Da pragmática da especialização fragmentada à pragmática da liofilização flexibilizada: as formas da educação no modo de produção capitalista . In: Germinal: Marxismo e Educação em Debate. V. 1 n. 1, Londrina: junho, 2009. Portal de Periódicos Científicos da UEL.

BARRETO, Raquel Goulart. As Tics e a formação de profissionais da Educação. In: PRADO, Eliane Mimesse, SOUZA, Maria Antonia de Souza, FERREIRA, Naura SYRIA Carapeto. Educação em Debate. Curitiba: UTP, 2009.

DOURADO, Luis Fernando. Políticas e Gestão da educação superior a distância: novos marcos regulatórios? In: Educação \& Sociedade. Campinas, vol. 29, n. 104. Especial, Out. 2008.

EVANGELISTA, Olinda, SHIROMA, Oto Shiroma. Redes para conversão docente. In: FIUZA, Alexandre, CONCEIÇÃO, Gilmar Henrique da. Política, Educação e Cultura. (ORGs.). Cascavel: EDUNIOESTE, 2008.

GATTI, Bernardete Angelina (Coord.). Professores do Brasil: impasses e desafios. Brasília: Unesco, 2009.

LIBÂNIO, Adeus professor, Adeus professora?: novas exigências educacionais $e$ profissão docente, 1998.

PEREIRA, M. F. R., PEIXOTO, E. M. de M. Formação e Trabalho Docente: Espaço da Luta de Classes. Anped, 2009.

PRADO, Maria Elisabette Brisola, SILVA, Maria da Graça Moreira da. Formação de educadores em ambientes virtuais de aprendizagem. Em Aberto, Brasília: vol. 22, n. 79, p. 61-74, jan. 2009.

SILVA, Welington Araújo Silva. As tecnologias da informação e comunicação no processo de formação humana via educação a distância. Boletim Germinal, n. 9, Nov. 2009. Portal de Periódicos Científicos da UEL.

VALENTE, José Armando (org.). O Computador na Sociedade do Conhecimento. Publicação: OEA_NIED/UNICAMP. http: www.nied.inicamp.br/oea.

Notas

${ }^{1}$ A Linguagem Logo foi desenvolvida em 1967, tendo como base a teoria de Piaget e algumas idéias da Inteligência Artificial (Papert, 1980), (VALENTE, p.3).

Artigo recebido em: 28/03/2010

Aprovado em: $13 / 12 / 2010$ 